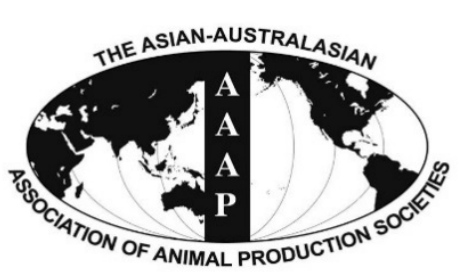

Open Access

Asian Australas. J. Anim. Sci.

Vol. 29, No. 1 : 80-88 January 2016

http://dx.doi.org/10.5713/ajas.15.0219

www.ajas.info

pISSN 1011-2367 elSSN 1976-5517

\title{
Effects of Elevated Crude Glycerin Concentrations on Feedlot Performance and Carcass Characteristics in Finishing Steers
}

\author{
P. Chanjula*, T. Raungprim ${ }^{1}$, S. Yimmongkol ${ }^{2}$, S. Poonko ${ }^{1}$, S. Majarune ${ }^{1}$, and W. Maitreejet ${ }^{1}$ \\ Department of Animal Science, Faculty of Natural Resources, \\ Prince of Songkla University, Songkhla 90112, Thailand
}

\begin{abstract}
Twenty crossbred steers $(400 \pm 40.1 \mathrm{~kg}$ of initial body weight) were used to assess the effects of a dietary supplementation with crude glycerin (CG) as a substitute for corn grain on performance, carcass traits, and meat quality. Four isocaloric and isonitrogenous diets were offered to the experimental animals ( 5 steers per treatment) for 121 days using randomized complete block design. The steers individually received dietary treatments containing $0 \%, 7 \%, 14 \%$, and $21 \%$ of CG ( $88.91 \%$ pure) on a dry matter (DM) basis. The diets were offered ad libitum as total mixed rations twice daily. Weight gain and carcass traits were determined. At the end of the experimental period, the harvest data and carcass characteristics of the steers were recorded, and meat quality was determined. No significant effect of CG inclusion was observed in any of the growth performance and carcass characteristics traits studied. Also, there were no apparent effects of diets $(\mathrm{p}>0.05)$ on meat quality $(\mathrm{pH}$, water holding capacity, drip losses, and cooking losses). The study concluded that CG could be used as a substitute for corn grain up to the level of approximately $21 \%$ of DM in the diets of finishing steers. (Key Words: Crude Glycerin, Growth Performance, Carcass Characteristic, Cattle)
\end{abstract}

\section{INTRODUCTION}

Feed is the biggest cost in livestock production, and the use of alternative feeds, such as by-products of biodiesel, may be a viable alternative both in economic and nutritional terms to increase profitability. For example, crude glycerin $(\mathrm{CG})$ is a by-product of biodiesel production resulting from the formation of methyl esters of fatty acids from triglycerides (Chanjula et al., 2015). CG is available because of the expansion of the biodiesel industry, and might be an optimal product for animal feeding (Donkin et al., 2009). Approximately, $7.9 \mathrm{~kg}$ of CG is generated per $100 \mathrm{~L}$ of biodiesel produced. Therefore, the increase of

\footnotetext{
* Corresponding Author: P. Chanjula. Tel: +66-74-558805, Fax: +66-74-558805, E-mail: pin.c@psu.ac.th

${ }^{1}$ Buffalo and Beef Production Research Center, Suwanvajokkasikit Animal Production Research and Development Institute, Kasetsart University, Kamphaeng Saen Campus 73140, Thailand.

${ }^{2}$ Department of Animal Science, Faculty of Agriculture, Kasetsart University, Kamphaeng Saen Campus 73140, Thailand.

Submitted Mar. 15, 2015; Revised May 11, 2015; Accepted Jun. 10, 2015
}

biodiesel production has led to an increase of glycerin stocks with a subsequent price reduction making glycerin a potential high energy feed source for ruminants (AvilaStagno et al., 2013). The energy values of corn, wheat, and glycerin are similar. Thus, glycerin may be an attractive feedstuff to replace corn or wheat and to enhance physical properties of pelleted diets. Several researchers have estimated the energy value of glycerol in beef, and concluded that it is similar to corn grain (Mach et al., 2009). Similarly, Lammers et al. (2008) found that CG containing of $86.95 \%$ pure glycerol had a metabolizable energy (ME) content of 3,207 kcal $/ \mathrm{kg}$, which was $94 \%$ the ME content of corn (NRC, 2000). Therefore, glycerin could be used as an energetic ingredient in animal diets instead of cereals (which are usually more expensive than glycerin).

In ruminants, different quantities of glycerin are converted to volatile fatty acids. Particularly, propionate and butyrate, at the expense of acetate, are directly absorbed from the digestive system and act as precursors for gluconeogenesis in the liver and can provide energy for cellular metabolism (Krehbiel, 2008). CG is an appealing 
by-product in feedlot diets because it is hypothesized that $\mathrm{CG}$ is primarily converted to propionate in the rumen and thus, is acting as a precursor for glucose synthesis. Researchers reported that $35 \%$ to $69 \%$ of the CG administered was used to produce propionate (Krehbiel, 2008). If CG increased propionate concentration, then an increased gain-to-feed (GF) would be expected. In addition, feeding glycerin may also improve feed digestibility and growth performance of cattle in a dose-dependent manner (Miller et al., 2001). However, GF responses have been variable. As dietary $\mathrm{CG}$ increased, average daily gain (ADG) and GF either did not change (Mach et al., 2009) or decreased (Pyatt et al., 2007) and responded quadratically (Parsons et al., 2009). Previous studies had assessed the effects of the inclusion of CG (above $86 \%$ of glycerol) in diets on intake, performance, carcass, and meat quality traits of beef cattle and reported acceptable inclusion of $10 \%, 12 \%$, and $8 \%$ respectively in diet dry matter (DM) (Pyatt et al., 2007; Mach et al., 2009; Parsons et al., 2009). Additionally, inclusions of $10 \%$ to $15 \%$ in diet DM have been used without adverse effects on milk production or milk composition (Donkin et al., 2009). However, there is little information available on feeding rates and production responses in finishing steers fed moderate to high amounts of glycerin regarding the effects of this by-product on their performance, carcass characteristics, and meat quality. This study hypothesized that CG was less fermented than corn starch, and this should be translated in animal performance and would produce similar growth performance and carcass characteristics as that of steers fed a diet without CG. Therefore, the objectives were to determine feedlot performance, carcass characteristics, and meat quality of finishing steers fed diets with $0 \%, 7 \%, 14 \%$, or $21 \% \mathrm{CG}$ formulated to an equal energy and crude protein (CP) content.

\section{MATERIALS AND METHODS}

All procedures involving animals in the metabolism and finishing studies were approved by the Ethical Principles for the Use of Animals for Scientific Purposes of the National Research Council of Thailand (NRCT).

\section{Animals, housing and experimental diets}

Twenty crossbred steers (approximately 25\% Thai native breed with the remainder represented by approximately 25\% Brahman, and 50\% Charolais breeds) with an average initial body weight (BW) of $400 \pm 40.1 \mathrm{~kg}$ and $24 \pm 4$ months of age were used in a randomized complete block design. They were distributed in 5 blocks to evaluate their intake and digestibility of nutrients, performance, carcass characteristics, and meat quality under feedlot conditions. Steers were blocked into 5 groups based on initial BW and allotted randomly to 1 of 4 treatments (n $=5$ steers per treatment) and were adapted to the experimental diets for $14 \mathrm{~d}$ before beginning of data collection. The steers were treated for internal and external parasites with Ivomex-F intramuscularly, vaccinated against Foot and Mouth Disease, and were kept in individual pens of approximately $12-\mathrm{m}^{2}(3.0 \times 4.0 \mathrm{~m})$ with concrete floor and free access to feed and water at all time. The experiment was conducted for $135 \mathrm{~d}$ (14 d for diet adaptation and 4 periods of $30 \mathrm{~d}$ for data collection). Four 4 corn-based dietary treatments consisted of $0 \%, 7 \%, 14 \%$, and $21 \%$ of CG (DM basis) and were formulated to be isonitrogenous (DM basis) to meet or exceed the NRC (2000) requirements of fattening steers. The ingredients and determined chemical composition of the components of each diet are presented in Table 1. The CG was produced in a palm-diesel

Table 1. Ingredients and chemical composition of diets containing increasing amounts of crude glycerin (\% DM basis)

\begin{tabular}{|c|c|c|c|c|}
\hline \multirow[t]{2}{*}{ Item } & \multicolumn{4}{|c|}{$\begin{array}{l}\text { Dietary crude glycerin } \\
\text { (\% of dietary DM) }\end{array}$} \\
\hline & 0 & 7 & 14 & 21 \\
\hline \multicolumn{5}{|l|}{ Ingredients composition (\%) } \\
\hline Crude glycerin ${ }^{1}$ & 0.0 & 7.0 & 14.0 & 21.0 \\
\hline Ground corn & 40.0 & 33.0 & 26.0 & 19.0 \\
\hline Cassava chip & 26.6 & 22.6 & 18.5 & 14.4 \\
\hline Palm kernel cake & 12.4 & 16.4 & 20.5 & 24.6 \\
\hline Leucaena leave meal & 10.0 & 10.0 & 10.0 & 10.0 \\
\hline Napier hay & 1.0 & 1.0 & 1.0 & 1.0 \\
\hline Molasses & 5.0 & 5.0 & 5.0 & 5.0 \\
\hline Salt & 0.2 & 0.2 & 0.2 & 0.2 \\
\hline Urea & 2.0 & 2.0 & 2.0 & 2.0 \\
\hline Mineral and vitamin $\operatorname{mix}^{2}$ & 1.0 & 1.0 & 1.0 & 1.0 \\
\hline Dicalcium phosphate & 1.0 & 1.0 & 1.0 & 1.0 \\
\hline $\begin{array}{l}\text { Sodium bicarbonate } \\
\left(\mathrm{NaHCO}_{3}(\right.\end{array}$ & 0.5 & 0.5 & 0.5 & 0.5 \\
\hline \multicolumn{5}{|c|}{ Analyzed nutrient content ${ }^{3}(\% \mathrm{DM})$} \\
\hline $\mathrm{DM}$ & 87.91 & 86.25 & 84.47 & 83.39 \\
\hline Ash & 4.59 & 4.71 & 4.86 & 5.20 \\
\hline $\mathrm{OM}$ & 95.41 & 95.29 & 95.14 & 94.48 \\
\hline $\mathrm{CP}$ & 13.95 & 13.98 & 13.95 & 13.92 \\
\hline EE & 2.64 & 2.49 & 2.34 & 2.22 \\
\hline NDF & 44.07 & 42.33 & 38.24 & 39.08 \\
\hline $\mathrm{ADF}$ & 19.44 & 19.97 & 20.00 & 19.07 \\
\hline $\mathrm{ME}^{4}(\mathrm{Mcal} / \mathrm{kg} \mathrm{DM})$ & 2.59 & 2.58 & 2.58 & 2.57 \\
\hline
\end{tabular}

DM, dry matter; OM, organic matter; $\mathrm{CP}$, crude protein; EE, ether extract; $\mathrm{NDF}$, neutral detergent fiber; ADF, acid detergent fiber; ME, metabolizable energy, TDN, total digestible nutrient.

${ }^{1}$ Contained $88.91 \%$ glycerol, $5.60 \%$ water, $2.24 \%$ sodium, and $0.52 \%$ methanol (Colorless, odorless, viscous liquid obtained from Biodiesel Producers, New Biodiesel, Surat Thani Province, Thailand).

${ }^{2}$ Minerals and vitamins (each $\mathrm{kg}$ contains): Vitamin A, 10,000,000 IU; Vitamin E, 70,000 IU; Vitamin D, 1,600,000 IU; Fe, 50 g; Zn, 40 g; Mn, $40 \mathrm{~g} ; \mathrm{Co}, 0.1 \mathrm{~g} ; \mathrm{Cu}, 10 \mathrm{~g} ; \mathrm{Se}, 0.1 \mathrm{~g} ; \mathrm{I}, 0.5 \mathrm{~g}$.

${ }^{3}$ Based on analysis of composite feed sample.

${ }^{4} \mathrm{ME}=\mathrm{TDN} \times 0.04409 \times 0.82(\mathrm{NRC}, 2000)$. Calculated with an estimated ME for glycerol of $3.47 \mathrm{Mcal} / \mathrm{kg}$ of DM (Mach et al., 2009). 
facility (New Biodiesel, Surat Thani Province, Thailand) and contained $88.91 \%$ of glycerin, $5.60 \%$ of water, $2.24 \%$ of sodium, and $0.52 \%$ of methanol (Table 2). Glycerin fed in the current study was used as an energetic ingredient. Therefore, to obtain 4 isoenergetic concentrates, the increase in glycerin content was counter balanced mainly by a decrease in cereal grain content. Palm-derived glycerin from single batch was added to the total mixed rations (TMR) as liquid.

After $14 \mathrm{~d}$ adaptation, the animals received diets in the form of a TMR twice daily in two equal portions at 0800 and $1600 \mathrm{~h}$ for 121 days. The amount of TMR offered and refused was recorded for each steer once daily, and the offered amount was adjusted to ensure approximately $10 \%$ of refusals after feeding. Feed refusals were weighed daily, analyzed for DM, recorded, and discarded to calculate dry matter intake (DMI), accurately. Individual feed ingredients were analyzed weekly for DM in order to adjust the diet composition for ingredient moisture content. Composite feed samples were collected weekly and dried in a forcedair oven at $60^{\circ} \mathrm{C}$ for $48 \mathrm{~h}$ to analyze DM. Dried samples were ground to pass a 1-mm screen (Cyclotech Mill, Tecator) and then analyzed for DM, CP, ether extract, and ash (AOAC, 1995). The tests for the evaluation of neutral detergent fiber and acid detergent fiber were determined according to Van Soest et al. (1991).

\section{Animal performance, slaughter, and sample collection}

All steers were weighed before the morning feeding at the beginning of the experiment and thereafter continued monthly at the same time of day and before transportation to the abattoir of the Institute of Animal Science (final BW). Daily DMI by each steer was estimated by summing the monthly intake and dividing by the number of days of the month. The ADG was calculated as the difference between the final and initial BW ( $16 \mathrm{~h}$ of fasting, only water was provided) divided by the number of days of feeding (121 d). Gain efficiency was calculated as ADG divided by DMI.

At the end of the experiment, the day before slaughter, the steers were transported to the experimental slaughterhouse after $121 \mathrm{~d}$ of study with a final BW of $514 \pm 46.9 \mathrm{~kg}$ and fasted overnight (only water was provided). All animals were slaughtered at a commercial beef plant. The animals were stunned by a captive bolt pistol, suspended by their hind legs and exsanguinated. The steers were slaughtered according to industrial practices in Thailand at a commercial slaughterhouse. After the slaughter, carcass dressing followed a standardized protocol without electrical stimulation as recommends by the National Livestock and Meat Board (Ziegler, 1977). Immediately following slaughter, hot carcass weight (HCW) was recorded, and hot dressing percentage (HDP) was defined as the ratio of $\mathrm{HCW}$ to slaughter $\mathrm{BW} \times 100$. All
Table 2. Chemical composition of crude glycerin used in this experiment ${ }^{1,2}$

\begin{tabular}{lcl}
\hline Items & Content & \multicolumn{1}{c}{ Analytical method } \\
\hline Total glycerin (\%) & 88.91 & $\begin{array}{l}\text { ASTM D 6584-00E01, titration } \\
\text { assay (AOAC,1995) }\end{array}$ \\
Moisture (\%) & 5.60 & AOAC $^{3}$ method 984.20 \\
DM (\%) & 94.40 & Determined by difference \\
Methanol $^{4}(\%)$ & 0.52 & Gas chromatography \\
Ash $^{4}(\%)$ & 3.51 & AOAC method 942.05 \\
Sodium $^{4}(\%)$ & 2.24 & AOAC methods 956.01, 9.15.01 \\
Sulfur $\left.{ }^{4} \%\right)$ & 0.10 & AOAC method 956.01 \\
Free fatty acid ${ }^{4}(\%)$ & 0.09 & AOAC method Ca 5a-40 \\
Crude protein ${ }^{4}(\%)$ & 0.01 & AOAC method 990.03 \\
Gross energy (kcal/kg) & 3,961 & Adiabatic bomb calorimeter \\
\hline${ }^{1}$ Crude glycerin was obtained from New Biodiesel Co., Ltd., Surat Thani \\
Province. \\
${ }^{2}$ Analysis by Central Laboratories (Songkhla, SK), Co., Ltd., Songkhla \\
90110, Thailand. \\
${ }^{3}$ AOAC (1995). \\
${ }^{4}$ Expressed as a percentage of crude glycerin DM.
\end{tabular}

carcasses were refrigerated at $4^{\circ} \mathrm{C}$ for approximately $24 \mathrm{~h}$, and then the cold carcass weight $(\mathrm{CCW})$ was recorded. Chilled dressing percentage (CDP) was calculated by $\mathrm{CCW}$ to slaughter $\mathrm{BW} \times 100$.

After the postmortem chill period, carcass $\mathrm{pH}\left(\mathrm{pH}_{24}\right)$, 12th rib fat thickness (RFT), and 12th rib longissimus muscle (LM) area were measured on the left side of each carcass after a cross-section cut was made between the 12th and 13th. Marbling score was measured in the LM between the 12th and 13th ribs by using the Thailand scoring system $(1=$ no marbling and $5=$ highest marbling). Meat color was determined by using a Subjective Color Score divided into 7 levels $(1=$ pale pink, $2=$ soft pink, $3=$ pink, $4=$ light red, $5=$ red, $6=$ medium dark red, and $7=$ dark red) (Smith et al., 2001). Meat colors preferred by consumers are ranges from soft pink to red color (from 2 to 4 ).

The muscular longissimus dorsi (LD) area was made on the left cut surface (of the chilled carcass) between rib 12th and 13th. The LD (the section between the last lumbar and the first sacral vertebrae) were collected. These cuts of meat, two per animal, were labeled and frozen immediately after collection for later measurement of color coordinates, water holding capacity (WHC), drip losses, cooking losses, and shear force characteristics.

\section{Meat quality}

Muscle surface color was measured objectively using a HunterLab Miniscan Plus Spectrocolorimeter on the same cut surface of the LD. Instrumental color measurements were recorded for $\mathrm{L}^{*}$ (measures darkness to lightness when lower $\mathrm{L}^{*}$ indicates a dark color), $\mathrm{a}^{*}$ (measures redness when higher $a^{*}$ value indicates a redder color), and $b^{*}$ (measures yellowness when higher $b^{*}$ value indicates a 
yellower color) at 3 locations of exposed lean to obtain a representative reading. To determine Warner-Bratzler shear force (WBSF), samples were defrosted at room temperature until their internal temperature reached $2^{\circ} \mathrm{C}$ to $5^{\circ} \mathrm{C}$. After weighing, samples were trimmed, and thin sections from the lateral and extremities were removed. Four LD samples, parallel to the muscle fibers and having $1 \mathrm{~cm}$ of thickness and $5 \mathrm{~cm}$ of length, were obtained to measure the shear force in a texture analyzer (TA-XTPlus-Texture Analyzer with a Warner-Bratzler Blade probe, Texture Expert Exponent-Stable Micro Systems software, Ltd in Godalming, Surrey, UK. SMS). For each sample, 6 shear force results were obtained. For the drip loss, the samples (2 $\mathrm{cm}$ thick) were packaged in clear trays of crystal polystyrene covered with a permeable film and stored at $4^{\circ} \mathrm{C}$. Drip loss was expressed as a percentage of the initial sample weight. The thawing loss and cooking loss were calculated as described by Vergara et al. (2003). The meat samples (two steaks, $2 \mathrm{~cm}$ thick) were placed in polyethylene bags and were heated at $75^{\circ} \mathrm{C}$ for $20 \mathrm{~min}$ in a water bath up to an internal temperature of $72^{\circ} \mathrm{C}$. The cooking loss was expressed as a percentage of the initial sample weight. Thawing loss was calculated as the difference between the weight of the steaks before and after thawing. All meat quality measurements were made in triplicate.

\section{Laboratory analyses}

Samples of feed and LD muscle were subjected to proximate analysis following the standard methods of AOAC (1995). Dry matter was determined by oven drying in a forced air oven at $105^{\circ} \mathrm{C}$ for $24 \mathrm{~h}$. The $\mathrm{N}$ content of feed and LD muscle was determined using a Kjeltec Auto Analyzer (Tecator, Hoganas, Sweden). Ether extract (EE) was determined in petroleum ether using a Soxtec Auto Analyzer (Tecator, Sweden). The ash content was determined by ashing the samples in a muffle furnace at $550^{\circ} \mathrm{C}$ for $5 \mathrm{~h}$. Neutral detergent fiber (NDF), acid detergent fiber (ADF), and lignin concentrations were determined by methods of Van Soest et al. (1991). NDF was analyzed without $\alpha$-amylase, and the values of NDF and ADF were expressed inclusive of residual ash. Lignin was obtained by treatment of ADF residue with $72 \%$ of sulfuric acid (Van Soest et al., 1991).

\section{Statistical analysis}

All data were analyzed using SAS (Cary, NC, USA) software. The MIXED procedure was used to analyze the fixed effects of treatment and block on performance and carcass characteristics, with animal serving as the experimental unit. Orthogonal contrasts were used to determine linear and quadratic effects, as well as the effect of the $0 \%$ of $\mathrm{CG}$ diet vs. the average of all diets containing
CG. Treatment means were statistically compared using Duncan's Multiple Range Test to identify differences between means. Contrasts were considered significant when the $p$-value was $\leq 0.05$, with tendencies declared at $p$-values between 0.05 and 0.10 .

\section{RESULTS AND DISCUSSION}

\section{Chemical composition of feeds}

The ingredients and chemical compositions of the experimental diets are presented in Table 1. The four experimental diets contained similar concentrations of ash, organic matter, CP, and EE. CG-based diets had a slightly lower NDF as proportion of CG in diets increased due to feeding of less of corn grain and cassava chip, ranging from $38.24 \%$ to $44.07 \%$, respectively. Palm kernel cake content increased as proportion of $\mathrm{CG}$ in diets decreased. The similarity in $\mathrm{ADF}$ for the $\mathrm{CG} 7 \%, 14 \%$, and $21 \%$ diets was unexpected. Additionally, the reason for the increase in ADF from $7 \%$ to $14 \% \mathrm{CG}$ is not known. The differences among TMR in fibrous components can be related to differences in the ingredients used in diet formulation (Table 1). The CG used in the present feeding trial was produced from crude palm oil contained $88.91 \%$ of glycerin, $2.24 \%$ of sodium, $0.52 \%$ of methanol, and less other compounds. Similar values for CG have been previously reported by Mach et al. (2009), Gunn et al. (2010a), AvilaStagno et al. (2013), Chanjula et al. (2015). The potential problematic compound in $\mathrm{CG}$ is methanol. Methanol toxicity in humans and animals is characterized by central nervous system depression, weakness, headache, vomiting, metabolic acidosis and optic disc oedema with the clinical consequences being blindness and/or Parkinsonian-like motor disease (Chanjula et al., 2015). However, methanol concentration can vary widely according to the manufacturing processes and should be monitored. To the authors' knowledge, no previous specification for the use of CG (with methanol) in animal feed has been published. Early studies of assessing the effects of feeding pure or crude glycerol to pigs (Schieck et al., 2010), and lambs (Avila-Stagno et al., 2013) provided initial evidence that glycerol can be used as a source of dietary energy for livestock. Based on the experimental data, no steers demonstrated clinical symptoms of methanol toxicity in the present study even though the diet with $21 \%$ of CG would contain $0.109 \%$, assuming that all the methanol in the CG remained in the feed. Moreover, the high-risk to health associated to methanol consumption due to inclusion of $\mathrm{CG}$ in diets of ruminant animals is not expected since methanol is naturally produced in the ruminal environment as a result of pectin digestion (Chanjula et al., 2015). 


\section{Intake and feedlot performance}

The effects of $\mathrm{CG}$ on growth performance of finishing steers are presented in Table 3. Overall initial BW, final BW, and $\mathrm{BW}$ gain were not significantly affected $(\mathrm{p}>0.05)$ by $\mathrm{CG}$ content for all dietary treatments as compared between the experimental diets ( $7 \%$ to $21 \%$ of $\mathrm{CG}$ ) with the control diet. No significant differences attributable to dietary treatment were observed in terms of total DMI (\% BW and $\left.\mathrm{g} / \mathrm{kg} \mathrm{BW}{ }^{0.75}\right)$; although the average DMI was numerically lower in glycerin-fed groups. This could imply that DMI was potentially regulated by the energy density of the diet. Literature data has established a correlation between dietary energy concentration and DMI. When cattle are consuming energy-dense high-concentrate diets, DMI is thought to be controlled by the animal's energetic demands and metabolic factors (NRC, 2000). Furthermore, conversion of glycerol to propionate by ruminal microbes (Roger et al., 1992) may lead to an observed decrease in DMI. Infusion of propionate into the portal vein or into the rumen (Oba and Allen, 2003) has been shown to reduce intake in sheep and cattle. Results of this study are in agreement with the study by Mach et al. (2009) who fed diets containing different contents of glycerin (up to $12 \%$ of DM) to Holstein bulls for $91 \mathrm{~d}$. Gunn et al. (2010a) and Chanjula et al. (2015) reported that there were no changes in DMI and digestibility when increasing concentrations of CG $(0 \%$ to $20 \%$ of DM) to replace dry rolled corn or corn grain in lamb and goat diets. Also, the addition of glycerin at levels up to $30 \%$ of DM fed to heavier lambs (Gomes et al., 2011) had no effect on their growth performance. Likewise, Avila-Stagno et al. (2013) used CG (up to $21 \%$ of DM) for finishing lambs without adverse effect on nutrient intakes and digestibility. In contrast, a decreased DM intake was reported when a diet containing $10 \%$ of glycerin as a corn replacement was fed to feedlot steers (Pyatt et al., 2007). Also, increasing glycerin to $4 \%, 8 \%, 12 \%$, and $16 \%$ of DM reduced DM intake in finishing heifers (Parsons et al., 2009). DM intakes particularly decreased when glycerin was fed to finishing lambs in high amounts up to $45 \%$ (Gunn et al., 2010b). According to Trabue et al. (2007), increasing lactic acid concentrations could depress CG fermentation in the rumen, thus altering (decreasing) DMI. However, it remains unclear whether this was due to the dietary treatment. Indeed, substituting corn with high levels of glycerin was reported to adversely affect ruminal fermentation through reducing fiber digestion, acetate production, and bacterial populations (Roger et al., 1992). Roger et al. (1992) demonstrated that introducing glycerol to the ruminal environment reduced cellulolytic activity of ruminal bacteria. Paggi et al. (2004) also reported that digestibility of other substrates in the diet might be inhibited with the inclusion of glycerol in an in vitro environment. However, there is more recent digestibility data which support results from the current study. Krehbiel (2008) reported that microorganisms adapted rapidly to glycerol feeding because elevated disappearance rates of glycerol were noted with increased days of glycerol feeding. Additionally, Hess et al. (2008) reported that CG could be added at $15 \%$ of DM to ruminant diets without negatively affecting to DM or fiber digestibility. These data, coupled with data from the current study, suggest that the ruminal environment, and concurrent decrease in DMI, might not be affected until CG concentrations exceeded to $21 \%$ of dietary DM. Further research, however, is needed to test this hypothesis and pinpoint the exact causes of decreased feedlot performance associated with elevated amounts $(>21 \%)$ of CG in the diet.

Table 3. Effects of dietary crude glycerin on performance and DMI of finishing steers

\begin{tabular}{|c|c|c|c|c|c|c|c|c|c|}
\hline \multirow{2}{*}{ Item } & \multicolumn{4}{|c|}{ Dietary crude glycerin $(\%)$} & \multirow{2}{*}{ SEM } & \multicolumn{4}{|c|}{ Contrasts, $\mathrm{p}$-value $^{1}$} \\
\hline & 0 & 7 & 14 & 21 & & $\mathrm{~L}$ & $\mathrm{Q}$ & $\mathrm{C}$ & 0 vs glycerin ${ }^{2}$ \\
\hline No. of steer & 5 & 5 & 5 & 5 & - & - & - & - & - \\
\hline Days on feed & 121 & 121 & 121 & 121 & - & - & - & - & - \\
\hline \multicolumn{10}{|l|}{ BW (kg) } \\
\hline Initial BW (kg) & 404.0 & 403.2 & 404.4 & 388.9 & 7.41 & 0.61 & 0.70 & 0.83 & 0.81 \\
\hline Final BW (kg) & 521.0 & 515.0 & 516.0 & 499.0 & 10.60 & 0.53 & 0.81 & 0.80 & 0.68 \\
\hline Weight gain $(\mathrm{kg})$ & 117.0 & 111.8 & 111.6 & 110.2 & 14.49 & 0.75 & 0.89 & 0.92 & 0.73 \\
\hline \multicolumn{10}{|l|}{ DMI } \\
\hline $\mathrm{kg} / \mathrm{d}$ & 7.79 & 7.50 & 7.55 & 7.25 & 0.39 & 0.47 & 0.99 & 0.75 & 0.52 \\
\hline$\% \mathrm{BW}$ & 1.69 & 1.62 & 1.65 & 1.63 & 0.08 & 0.67 & 0.80 & 0.73 & 0.57 \\
\hline $\mathrm{g} / \mathrm{kg}$ of $\mathrm{BW}^{0.75}$ & 78.28 & 75.42 & 76.25 & 74.80 & 3.75 & 0.58 & 0.85 & 0.73 & 0.53 \\
\hline $\operatorname{ADG}(\mathrm{kg} / \mathrm{d})$ & 0.968 & 0.932 & 0.920 & 0.920 & 0.12 & 0.77 & 0.88 & 0.98 & 0.75 \\
\hline $\operatorname{ADG}\left(\mathrm{g} / \mathrm{kg} \mathrm{W} \mathrm{W}^{0.75}\right)$ & 9.81 & 9.32 & 9.26 & 9.41 & 1.19 & 0.81 & 0.79 & 0.96 & 0.73 \\
\hline Feed efficiency & 0.124 & 0.122 & 0.121 & 0.125 & 0.01 & 0.96 & 0.83 & 0.92 & 0.95 \\
\hline
\end{tabular}

DMI, dry matter intake; SEM, standard error of the mean $(n=5)$; BW, body weight; ADG, average daily gain.

${ }^{1}$ Treatment and contrast p-values; p-value for L, linear effect; Q, quadratic effect; C, cubic effect.

${ }^{2}$ Compares the effects of $0 \%$ glycerin with the combined glycerin treatment. 
Likewise, partial dietary replacement of corn grain with CG did not significantly affect the average daily gain (ADG) $(0.935 \pm 0.02 \mathrm{~kg} / \mathrm{d})$ and feed efficiency of steers $(0.123 \pm 0.00$ $\mathrm{kg} / \mathrm{kg}$ ) in this study. Therefore, there were no differences in average daily gain in the overall fattening period as indicated by the treatment effect. Similarly, feeding CG up to $10 \%$ of DM did not affect ADG and feed efficiency in cattle (Pyatt et al., 2007; Mach et al., 2009; Parsons et al., 2009). Pyatt et al. (2007) reported an $11.4 \%$ and $21.9 \%$ of improvement in ADG and efficiency when glycerin replaced $10 \%$ of the dry-rolled corn in the diet but ADG and efficiency improved by only $2.5 \%$ and $16.4 \%$ when glycerin replaced $10 \%$ of the dry-rolled corn in diets also containing $30 \%$ of distillers grains. Similarly to the results of this study, glycerin as an energy ingredient effectively replaced dryrolled corn in the diet up to $20 \%$ of DM for finishing lambs had no negative impact on cumulative ADG and feed efficiency (Gunn et al., 2010a). Also, the addition of glycerin at levels up to $30 \%$ of DM fed to heavier lambs had no effect on their growth performance (Gomes et al., 2011). Conversely, Parsons et al. (2009), and Gunn et al. (2010b) demonstrated that feeding $\mathrm{CG}$ to finishing ruminants (finishing heifers and lambs) above $15 \%$ of DM decreased feed efficiency through decreased ADG. Data from the current study demonstrated that feeding $\mathrm{CG}$ up to $21 \%$ of dietary DM might have a positive impact on steer performance.

\section{Carcass characteristics and meat quality}

Carcass characteristics are presented in Table 4. No significant effect of dietary CG was observed on fasted live weight, $\mathrm{HCW}, \mathrm{CCW}$, dressing percentage, and weight loss. The lack of effects of $\mathrm{CG}$ inclusion on $\mathrm{HCW}$ and dressing percentage are in accordance with previous reports in lambs and goats (Gunn et al., 2010a; Avila-Stagno et al., 2013; Chanjula et al., 2015) and beef cattle (Mach et al., 2009; Françozo et al., 2013) that no effects on carcass traits found when replacing corn and barley grain with $\mathrm{CG}$ in concentrations of up to $21 \%$ and $18 \%$ of DM, respectively. CG seems to provide a similar amount of metabolizable energy as barley when CG is converted into volatile fatty acids (VFA) in the rumen (Mach et al., 2009). VFA provide energy to the animal. This fact permits normal growth and normal carcass values which were found in this study. The dressing percentage was similar in all steers and within the previously published range of $61.5 \%$ to $62.1 \%$ (Egea et al., 2014 ) in feedlot with a high energy density diet. Thus, the inclusion of CG in the studied levels had no effect on the dressing percentage in beef cattle finished in feedlot. However, Parsons et al. (2009) found that HCW increased by $8.1,5.1$, and $3.2 \mathrm{~kg}$ when glycerin was fed at $2 \%, 4 \%$, and $8 \%$, respectively, but $\mathrm{HCW}$ decreased by 1.2 and $9.1 \mathrm{~kg}$ when glycerin was fed at $12 \%$ and $16 \%$, respectively. An explanation for this might be the lower intake, water intake, and digestibility of the diet and nutrients of feed when glycerin is used up to $10 \%$ (Chanjula et al., 2015). Likewise,

Table 4. Effects of dietary crude glycerin on carcass characteristics of finishing steers

\begin{tabular}{|c|c|c|c|c|c|c|c|c|c|}
\hline \multirow{2}{*}{ Item } & \multicolumn{4}{|c|}{ Dietary crude glycerin (\%) } & \multirow{2}{*}{ SEM } & \multicolumn{4}{|c|}{ Contrasts, $p$-value $^{1}$} \\
\hline & 0 & 7 & 14 & 21 & & $\mathrm{~L}$ & Q & $\mathrm{C}$ & 0 vs glycerin ${ }^{2}$ \\
\hline Fasted live weight (kg) & 474.6 & 487.8 & 484.2 & 471.2 & 11.76 & 0.89 & 0.59 & 0.94 & 0.81 \\
\hline HCW (kg) & 289.2 & 297.8 & 293.8 & 285.6 & 9.17 & 0.82 & 0.57 & 0.89 & 0.85 \\
\hline CCW (kg) & 283.2 & 291.5 & 287.9 & 279.7 & 8.93 & 0.82 & 0.57 & 0.91 & 0.85 \\
\hline Dressing percentage (\%) & 60.8 & 60.9 & 60.8 & 61.1 & 1.02 & 0.89 & 0.89 & 0.84 & 0.93 \\
\hline Cold dressing percentage $(\%)$ & 59.63 & 59.70 & 59.58 & 59.88 & 1.01 & 0.87 & 0.90 & 0.88 & 0.93 \\
\hline Weight loss $(\mathrm{kg})$ & 5.94 & 6.26 & 5.84 & 5.86 & 0.31 & 0.74 & 0.73 & 0.55 & 0.92 \\
\hline Weight loss $(\%)$ & 1.24 & 1.27 & 1.20 & 1.25 & 0.05 & 0.77 & 0.85 & 0.30 & 0.95 \\
\hline $\mathrm{LM} \operatorname{area}^{3}\left(\mathrm{~cm}^{2}\right)$ & 71.60 & 75.22 & 72.30 & 74.50 & 2.75 & 0.77 & 0.87 & 0.56 & 0.64 \\
\hline WBSF (kg) & 5.82 & 6.49 & 6.36 & 6.75 & 0.35 & 0.12 & 0.71 & 0.43 & 0.11 \\
\hline $\mathrm{KPH} \mathrm{fat}{ }^{4}(\mathrm{~kg})$ & 22.72 & 24.48 & 24.42 & 25.68 & 1.84 & 0.43 & 0.91 & 0.77 & 0.45 \\
\hline KPH fat (\%) & 4.81 & 5.00 & 5.00 & 5.43 & 0.41 & 0.32 & 0.77 & 0.73 & 0.48 \\
\hline Back fat thickness $(\mathrm{cm})$ & 1.80 & 1.92 & 1.76 & 1.62 & 0.09 & 0.14 & 0.22 & 0.52 & 0.78 \\
\hline Marbling score ${ }^{5}$ & 2.0 & 2.0 & 2.0 & 1.8 & 0.09 & 0.19 & 0.33 & 0.66 & 0.57 \\
\hline Meat color ${ }^{6}$ & 3.86 & 3.32 & 3.76 & 3.75 & 0.13 & 0.67 & 0.61 & 0.79 & 0.31 \\
\hline
\end{tabular}

SEM, standard error of the mean $(\mathrm{n}=5)$; HCW, hot carcass weight; $\mathrm{CCW}$, cold carcass weight; LM, longissimus dorsi; WBSF, Warner-Bratzler shear force;

${ }^{1}$ Treatment and contrast p-values; p-value for L, linear effect; Q, quadratic effect; C, cubic effect.

${ }^{2}$ Compares the effects of $0 \%$ glycerin with the combined glycerin treatment.

${ }^{3} \mathrm{LM}$, longissimus muscle area, $\mathrm{cm}^{2}$.

${ }^{4} \mathrm{KPH}$ (kidney, pelvic, and heart fat) as a percentage of carcass weight.

${ }^{5}$ Marbling score from 1 to 5; $1=$ no marbling and $5=$ highest marbling (Sethakul and Opatpatanakit, 2005).

${ }^{6}$ Meat color score from 1 to $7 ; 1=$ pale pink, $2=$ soft pink, $3=$ pink, $4=$ light red, $5=$ red, $6=$ medium dark red, and $7=$ dark red $($ Smith et al., 2001$)$. 
the area and WBSF of LM, kidney, pelvic, and heart (KPH) fat, and fat thickness were not affected by treatments. Similarly, Bartoň et al. (2013) found that a long-term dietary treatment with $\mathrm{CG}$ as a replacement of barley meal up to the level of $10 \%$ of DM had no significantly effect on any of the bull carcass and meat quality traits studied. On the other hand, Parsons et al. (2009) observed a linear reduction in the LM area and subcutaneous fat when increasing the amounts of glycerin fed (up to 16\%). Nevertheless, the obtained WBSF results $(<4.0 \mathrm{~kg})$ ensure a tenderness that should result in high consumer acceptance (Miller et al., 2001).

No differences $(p>0.05)$ were reported in marbling and color scores when corn was replaced by CG in the diets of steers finished in feedlot. Marbling score was classified as "light" or "small" (1.95 points). Although medium marbled meat is well accepted within the home market, beef should feature more accentuated marbling to be acceptable in foreign markets. Parsons et al. (2009) observed that the inclusion of glycerin $(16 \%)$ in the diets for heifers had led to a linear decrease in marbling scores. Because glycerin reduced subcutaneous fat, it is conceivable that glycerin may alter fat deposition, which might explain the observed reductions in marbling scores. Glucose was previously shown to be quantitatively the primary lipid precursor in intramuscular adipose tissue whereas the relative contribution of acetate to lipogenesis was greatest in subcutaneous adipose tissue (Parsons et al., 2009). Previous research suggests that increasing the glucogenic substrates (e.g., glycerin) fed to cattle results in increased marbling scores (Mach et al., 2009). Unlike in our study, it has been previously reported that glycerin increased ruminal propionic and butyric acid concentrations at the expense of acetic acid concentration (Chanjula et al., 2015). Therefore, lower concentrations of acetic acid as a lipogenic precursor could have been the reason why glycerin supplemented diets reduced in both subcutaneous fat and marbling scores in feedlot heifers fed increasing quantities of CG (Parsons et al., 2009) and decreased LD ether extract values in finishing lambs (Gunn et al., 2010b). However, glycerin showed no positive effects on marbling when various concentrations were fed to feedlot heifers. The meat color was similar for all treatments. According to Mancini and Hunt (2005), meat color is an important commercial characteristic that influences consumer behavior. Meat color was considered good (3.67 points), ranging between "red" and "slightly dark red". Adequate nutrition and low age may have affected meat color (Mancini and Hunt, 2005).

Table 5 shows the effect of CG inclusion in the animal diet on meat quality parameters. CG inclusion had no effect $(\mathrm{p}>0.05)$ on the $\mathrm{pH}$ of meat $45 \mathrm{~min}$ and $24 \mathrm{~h}$ after slaughter or on the colorimetric parameters of LD among treatments. These results agreed with Mach et al. (2009) who supplemented CG in Holstein bull diets. Similarly, Françozo et al. (2013) found no differences between control and CG $(5 \%$ and $12 \%)$ groups in Nellore bull meat. Pearce et al. (2011) reported that the lightness $\left(\mathrm{L}^{*}\right)$ was influenced by the amount of water on the meat surface and was a consequence of water retention capacity which in turn affected the $\mathrm{pH}$. Therefore, LM water loss was not affected by diet when CG was supplemented in the diets. Lightness, redness, and yellowness on LM were normal for bulls finished in feedlot (Bartoñ et al., 2013). According to Mancini and Hunt (2005), changes in muscle color for $\mathrm{L}^{*}$ and $b^{*}$ can be attributed to diet and can affect the marbling score and muscle glycogen levels in the pre-slaughter.

Table 5. Physico-chemical characteristics of beef of steers fed different levels of crude glycerin

\begin{tabular}{|c|c|c|c|c|c|c|c|c|c|}
\hline \multirow{2}{*}{ Item } & \multicolumn{4}{|c|}{ Dietary crude glycerin $(\%)$} & \multirow{2}{*}{ SEM } & \multicolumn{4}{|c|}{ Contrasts, $\mathrm{p}$-value $^{1}$} \\
\hline & 0 & 7 & 14 & 21 & & $\mathrm{~L}$ & Q & $\mathrm{C}$ & 0 vs glycerin \\
\hline $45 \min \mathrm{pH}^{3}$ & 6.54 & 6.41 & 6.46 & 6.50 & 0.07 & 0.78 & 0.20 & 0.57 & 0.27 \\
\hline $24 \mathrm{~h} \mathrm{pH}^{4}$ & 6.10 & 6.09 & 6.11 & 6.11 & 0.02 & 0.86 & 0.83 & 0.75 & 0.94 \\
\hline \multicolumn{10}{|l|}{ Color of $\mathrm{LM}^{5}$} \\
\hline $\mathrm{L}^{*}$ & 38.64 & 38.81 & 36.04 & 39.92 & 1.79 & 0.89 & 0.31 & 0.25 & 0.85 \\
\hline$a^{*}$ & 17.32 & 18.03 & 18.57 & 17.92 & 0.79 & 0.56 & 0.45 & 0.80 & 0.42 \\
\hline$b^{*}$ & 8.67 & 10.66 & 8.71 & 10.24 & 1.01 & 0.53 & 0.81 & 0.10 & 0.30 \\
\hline WHC & 73.10 & 72.81 & 71.32 & 72.21 & 2.56 & 0.71 & 0.83 & 0.55 & 0.61 \\
\hline Drip loss (\%) & 1.68 & 1.70 & 1.66 & 1.70 & 0.12 & 0.97 & 0.93 & 0.80 & 0.96 \\
\hline Thawing loss $(\%)$ & 11.57 & 10.64 & 11.62 & 12.19 & 1.46 & 0.63 & 0.57 & 0.69 & 0.95 \\
\hline Cooking loss (\%) & 21.70 & 24.53 & 21.22 & 20.71 & 2.26 & 0.50 & 0.42 & 0.33 & 0.84 \\
\hline
\end{tabular}

SEM, standard error of the mean ( $\mathrm{n}=5)$; LM, longissimus dorsi; WHC, water holding capacity

${ }^{1}$ Treatment and contrast p-values; p-value for L, linear effect; Q, quadratic effect; C, cubic effect

${ }^{2}$ Compares the effects of $0 \%$ glycerin with the combined glycerin treatment.

${ }^{3} \mathrm{pH}$ measurements taken at 45 min after slaughter.

${ }^{4} \mathrm{pH}$ measurements taken at $24 \mathrm{~h}$ after slaughter.

${ }^{5} \mathrm{~L}^{*}$ values are a measure of lightness (higher value indicates a lighter color); a* values are a measure of redness (higher value indicates a redder color); $b^{*}$ values are a measure of yellowness (higher value indicates a more yellow color), by CIE, complete international commission on illumination (Hunter color flex). 
However, the possible increase in energy levels, resulting from supplementation with glycerin and interference in the final characteristics of the meat, was not enough to give result in color changes. There was no dietary effect $(p>0.05)$ of $\mathrm{CG}$ inclusion on WHC, drip loss, thawing loss, or cooking loss. In contrast, studies in non-ruminants found different results for these parameters. Also, Mourot et al. (1994) found a reduction in water losses and cooking losses in pigs fed $5 \%$ of glycerol because the glycerol increased cell osmotic pressure, increasing the intracellular water content, which would increase the WHC. These differences between species may be explained with the fact that glycerol is absorbed without being transformed the pig stomach, while in ruminants, $80 \%$ of glycerol is transformed in the rumen into volatile fatty acids (Mach et al., 2009), so suggesting a low absorption of the unchanged glycerol molecule. Consequently, water holding parameters in ruminant meat may not be altered by glycerol feeding, as is demonstrated in the current study and previously in beef (Mach et al., 2009; Françozo et al., 2013).

\section{CONCLUSION}

CG was a good an alternative energy source to substitute for corn grain in the diets. Results from current study demonstrated that a diet with up to $21 \%$ of CG could be fed to finishing steers with no effect on growth performance, carcass characteristics, and meat quality traits studies. Thus, in the case of competitive pricing, CG may be effectively used as an alternative energy source to substitute for cereals in the diets of finishing steers. However, the effects of glycerin metabolism on LM fatty acid composition needs further research.

\section{CONFLICT OF INTEREST}

We certify that there is no conflict of interest with any financial organization regarding the material discussed in the manuscript.

\section{ACKNOWLEDGMENTS}

The authors would like to express the most sincere gratitude and appreciation to the Faculty of Natural Resources, Prince of Songkla University for financial support of this research (Project no. NAT550821S) and to the Buffalo and Beef Production Research Center, Suwanvajokkasikit Animal Production Research and Development Institute at Kasetsart University for allowing use of the research facilities. This work was also supported by the Tropical Feed Resources Research and Development Center (TROFREC), Department of Animal Science, Faculty of Agriculture, Khon Kaen University.

\section{REFERENCES}

AOAC. 1995. Official Methods of Analysis. 16th ed. Assoc. Official Analytical Chemist, Arlington, VA, USA.

Avila-Stagno, J., A. V. Chaves, M. L. He, O. M. Harstad, K. A. Beauchemin, S. M. McGinn, and T. A. McAllister. 2013. Effects of increasing concentrations of glycerol in concentrate diets on nutrient digestibility, methane emissions, growth, fatty acid profiles, and carcass traits of lambs. J. Anim. Sci. 91:829837.

Bartoñ, L., D. Bureš, P. Homolka, F. Jančík, M. Marounek, and D. Řehák. 2013. Effects of long-term feeding of crude glycerine on performance, carcass traits, meat quality, and blood and rumen metabolites of finishing bulls. Livest. Sci. 155:53-59.

Chanjula, P., P. Pakdeechanuan, and S. Wattanasit. 2015. Effects of feeding crude glycerin on feedlot performance and carcass characteristics in finishing goats. Small Rumin. Res. 123:95102.

Donkin, S. S., S. L. Koser, H. M. White, P. H. Doane, and M. J. Cecava. 2009. Feeding value of glycerol as a replacement for corn grain in rations fed to lactating dairy cows. J. Dairy Sci. 92:5111-5119.

Egea, M., M. B. Linares, M. D. Garrido, C. Villodre, J. Madrid, J. Orengo, S. Martínez, and F. Hernández. 2014. Crude glycerine inclusion in Limousin bull diets: Animal performance, carcass characteristics and meat quality. Meat Sci. 98:673-678.

Françozo, M. C., I. N. Prado, U. Cecato, M. V. Valero, F. Zawadzki, O. L. Ribeiro, R. M. Prado, and J. V. Visentainer. 2013. Growth performance, carcass characteristics and meat quality of finishing bulls fed crude glycerine-supplemented diets. Braz. Arch. Biol. Technol. 56:327-336.

Gomes, M. A. B., G. V. DeMoraes, M. Mataveli, F. D. F. DeMacedo, C. Carneiro, and R. M. Rossi. 2011. Performance and carcass characteristics of lambs fed on diets supplemented with glycerin from biodiesel production. Rev. Bras. Zootec. 40:2211-2219.

Gunn, P. J., M. K. Neary, R. P. Lemenager, and S. L. Lake. 2010a. Effects of crude glycerin on performance and carcass characteristics of finishing wether lambs. J. Anim. Sci. 88:1771-1776.

Gunn, P. J., A. F. Schultz, M. L. Van Emon, M. K. Neary, R. P. Lemenager, C. P. Rusk, and S. L. Lake. 2010b. Effects of elevated crude glycerin concentrations on feedlot performance, carcass characteristics, and serum metabolite and hormone concentrations in finishing ewe and wether lambs. Prof. Anim. Sci. 26:298-306

Hess, B. W., S. L. Lake, and S. A. Gunter. 2008. Using glycerin as a supplement for forage-fed ruminants. J. Anim. Sci. 86(ESuppl. 2):392 (Abstr.)

Krehbiel, C. R. 2008. Ruminal and physiological metabolism of glycerin. J. Anim. Sci. 86(E-Suppl. 2):392 (Abstr.).

Lammers, P. J., B. J. Kerr, T. E. Weber, W. A. Dozier, III, M. T. Kidd, K. Bregendahl, and M. S. Honeyman. 2008. Digestible and metabolizable energy of crude glycerol for growing pigs. J. Anim. Sci. 86:602-608.

Mach, N., A. Bach, and M. Devant. 2009. Effects of crude glycerin supplementation on performance and meat quality of Holstein bulls fed high-concentrate diets. J. Anim. Sci. 87:632-638.

Mancini, R. A. and M. C. Hunt. 2005. Current research in meat 
color. Meat Sci. 71:100-121.

Miller, M., M. Carr, C. Ramsey, K. Crocket, and L. Hoover. 2001. Consumer thresholds for establishing the value of beef tenderness. J. Anim. Sci. 79:3062-3068.

Mourot, J., A. Aumaitre, A. Mounier, P. Peiniau, and A. C. François. 1994. Nutritional and physiological effects of dietary glycerol in the growing pig. Consequences on fatty tissues and post mortem muscular parameters. Livest. Prod. Sci. 38:237244.

NRC. 2000. Nutrient Requirements of Beef Cattle, 7th ed. Natl. Acad. Press, Washington, DC, USA.

Oba, M. and M. S. Allen. 2003. Intraruminal infusion of propionate alters feeding behavior and decreases energy intake of lactating dairy cows. J. Nutr. 133:1094-1099.

Paggi, R. A., J. P. Fay, and C. Faverin. 2004. In vitro ruminal digestibility of oat hay and cellulolytic activity in the presence of increasing concentrations of short-chain acids and glycerol. J. Agric. Sci. 142:89-96.

Parsons, G. L., M. K. Shelor, and J. S. Drouillard. 2009. Performance and carcass traits of finishing heifers fed crude glycerin. J. Anim. Sci. 87:653-657.

Pearce, K. L., K. Rosenvold, H. J. Andersen, and D. L. Hopkins. 2011. Water distribution and mobility in meat during the conversion of muscle to meat and ageing and the impacts on fresh meat quality attributes - A review. Meat Sci. 89:111-124.
Pyatt, A., P. H. Doane, and M. J. Cecava. 2007. Effect of crude glycerin in finishing cattle diets. J. Anim. Sci. 85(Suppl. 1):530 (Abstr.).

Roger, V., G. Fonty, C. Andre, and P. Gouet. 1992. Effects of glycerol on the growth, adhesion, and cellulolytic activity of ruminal cellulolytic bacteria and anaerobic fungi. Curr. Microbiol. 25:197-201.

Schieck, S. J., B. J. Kerr, S. K. Baidoo, G. C. Shurson, and L. J. Johnston. 2010. Use of crude glycerol, a biodiesel coproduct, in diets for lactating sows. J. Anim. Sci. 88:2648-2656.

Smith, G. C., D. B. Griffin, and H. K. Johnson. 2001. Meat Evaluation Handbook. American Meat Science Association, Champaign, IL, USA.

Trabue, S., K. Scoggin, S. Tjandrakusuma, M. A. Rasmussen, and P. J. Reilly. 2007. Ruminal fermentation of propylene glycol and glycerol. J. Agric. Food Chem. 55:7043-7051.

Van Soest, P. J., J. B. Robertson, and B. A. Lewis. 1991. Methods for dietary fiber, neutral detergent fiber, and nonstarch polysaccharides in relation to animal nutrition. J. Dairy Sci. 74:3583-3597.

Vergara, H., L. Gallego, A. García, and T. Landete-Castillejos. 2003. Conservation of Cervus elaphus meat in modified atmospheres. Meat Sci. 65:779-783.

Ziegler, J. H. 1977. The Meat We Eat. The Interstate Printers, Danville, IL, USA. 